\title{
Deflating Deflationary Truthmaking
}

\author{
Jamin Asay \\ Sam Baron \\ University of Hong Kong University of Western Australia \\ Forthcoming in Philosophical Quarterly
}

\begin{abstract}
In this paper we confront a challenge to truthmaker theory that is analogous to the objections raised by deflationists against substantive theories of truth. Several critics of truthmaker theory espouse a "deflationary" attitude about truthmaking, though it has not been clearly presented as such. Our goal is to articulate and then object to the underlying rationale behind deflationary truthmaking. We begin by developing the analogy between deflationary truth and deflationary truthmaking, and then show how the latter can be found in the work of Dodd, Hornsby, Schnieder, Williamson, and others. These philosophers believe that the ambitions of truthmaker theory are easily satisfied, without recourse to ambitious ontological investigation-hence the analogy with deflationary truth. We argue that the deflationists' agenda fails: there is no coherent deflationary theory of truthmaking. Truthmaking, once deflated, fails to address the questions at the heart of truthmaking investigation. Truthmaking cannot be had on the cheap.
\end{abstract}

Keywords: truthmaking, truth, deflationism, dependence, B-schema, T-schema

\section{Introduction}

As the literature on truthmaking continues to grow, its detractors remain steadfast in their opposition. These critics generally agree that truthmaker theorists do not succeed in accomplishing the tasks they set out for themselves, or do so at too great a theoretical and ontological cost. The ambitions of truthmaker theory, so says the objector, can be satisfied in a far simpler and more economical way, leaving the truthmaker theorist's posits and commitments unmotivated and unjustified. This sort of objection is the focus of our paper, as we feel it captures much of the negative sentiment that surrounds truthmaker theory, although it has not been satisfactorily 
articulated and addressed. By meeting this objection directly, we hope to nullify some of the broad skepticism that currently exists toward the truthmaking program, and encourage its critics to find new ways of challenging the theory.

There are many ways of objecting to truthmaker theory. Some criticisms target particular versions of truthmaker theory; others object only to some ambitions of truthmaker theory, while leaving others alone. Our concern is with those who dismiss outright the very project of truthmaker theory, as well as those who think that truthmaking's goals can be easily met in ways that render most truthmaking investigation superfluous. We see these two attitudes as basically the same: if standard inquiry into truthmaking is thoroughly misguided, then one should either reject the whole domain outright, or-if one still wants to countenance the basic idea behind truthmaking-hold on to the language of truthmaking, but show how it requires none of the substance usually attributed to it.

It is this idea-that truthmaking can be had at no substantive ontological cost — that we call deflationary truthmaking. We give it this name because it is closely analogous to the deflationary theory of truth. Moreover, proponents of deflationary truthmaking employ a dialectical strategy quite similar to the one used to defend deflationism about truth. As we shall argue, however, there is no defensible deflationary theory of truthmaking to be found. ${ }^{1}$

We begin by zeroing in on our target by first drawing out the analogy between deflationary truth and deflationary truthmaking ( $(2)$; then we show how deflationary attitudes toward truthmaking have figured into the critiques of several prominent opponents to truthmaker theory, and sharpen up the view $(\$ 3)$. We then articulate exactly why this attitude toward truthmaking is indefensible, and does not, contrary to its proponents' claims, satisfy the ambitions of truthmaker theory $(\$ 4-5)$.

\section{An Analogy: Deflationary Truth}

The deflationary attitude toward truth can be summed up as the thought that the traditional theories of truth (correspondence, coherentist, pragmatic) are overreactions to the goal of trying to understand the nature of truth. ${ }^{2}$ Instead of giving an account of truth heavy with metaphysical implications, the deflationist offers a stark, austere theory that nevertheless gives a complete account of how truth figures into our language and thought. When it comes to correspondence

\footnotetext{
${ }^{1}$ Note that our topic is not what Vision (2005) calls deflationary truthmaking, which concerns what deflationists about truth should believe about truthmaking.

${ }^{2}$ E.g. Horwich 1990.
} 
theory, say, a common deflationist stance is that the idea or language of correspondence is in some sense correct, but that it can be accommodated without invoking a commitment to worldly entities called 'facts' or a correspondence relation. ${ }^{3}$ In spite of their deflationary attitude, however, deflationists have no qualms or unease about the notion of truth itself. Truth isn't to deflationists what substance or scholastic necessary connections were to Hume. Deflationists do not commit truth to the flames.

In sum, we understand the deflationist as accepting the following central commitments:

(1) The notions of truth and correspondence are philosophically acceptable.

(2) The notions of truth and correspondence do not require substantive ontological commitments for their acceptance.

The bulk of deflationists' writing is given over to defending (2), and showing how their sparse theory can countenance all of the important dimensions of truth. Deflationists often argue that while it is platitudinous that truths correspond with reality, this idea is perfectly captured by instances of the truth-schema:

(T) ' $p$ ' is true if and only if $p$.

We propose that one can understand the opposition to truthmaker theory by way of analogy with deflationists' opposition to substantive theories of truth. The deflationist about truthmaking believes that while the language of truthmaking might be admissible, truthmaking can be accommodated without taking on the substantive ontological commitments that typically characterize truthmaker theory. ${ }^{4}$ The deflationist about truthmaking, then, accepts the following theses:

$(1 *) \quad$ The notion of truthmaking is philosophically acceptable.

$\left(2^{*}\right) \quad$ The notion of truthmaking does not require substantive ontological commitments for its acceptance.

\footnotetext{
${ }^{3}$ E.g. Blackburn 1984: 225, Horwich 1990: 110, and Quine 1990: 93.

${ }^{4}$ For defenses of non-deflationary truthmaker theory, see Armstrong 2004, Rodriguez-Pereyra 2005, Cameron 2008a, Saenz 2014, Simpson 2014, Griffith 2015, and Jago 2018.
} 
Just as deflationists and substantivists about truth tend to agree on (1) and disagree about (2), we think that deflationists and substantivists about truthmaking tend to agree on $\left(1^{*}\right)$ and disagree about $\left(2^{*}\right)$. The analogy isn't perfect. Some critics of truthmaking would certainly be happy to do away with the language of truthmaking altogether, whereas no deflationist about truth advocates abandoning 'truth'. 'Truthmaking', after all, is a term of philosophical art. Still, the deflationists we have in mind largely accept $\left(1^{*}\right)$, and are mostly interested in defending $\left(2^{*}\right)$. In so doing, they hope to pull the rug out from underneath the truthmaker theorist: since the demands of truthmaker theory are easily met, there is nothing left for self-styled truthmaker theorists to do.

\section{Deflationists about Truthmaking}

We believe that deflationary attitudes about truthmaking can be detected in the work of a number of different critics of truthmaker theory. ${ }^{5}$ One particularly salient case is Jennifer Hornsby, who writes: "I shall make a suggestion about why we should be apt to have the intuition that truth is grounded and thus to think of 'truth making', even if there are no entities which make propositions true" (2005: 33). This sounds like an endorsement of $\left(1^{*}\right)$ and $\left(2^{*}\right)$ : she wants to capture the basic idea behind truthmaking without actually committing to the substantive ontological posits made by truthmaker theories. In fact, Hornsby's paper is entitled "Truth without Truthmaking Entities", which suggests the deflationist perspective that truthmaker theory's ambitions can be satisfied without resorting to truthmaker theory at all. ${ }^{6}$ What Hornsby identifies as the core concern of truthmaker theory is explaining "a certain asymmetry in our thinking about truth", which is that any proposition $\langle p\rangle$ is true because $p$, but that it's not the case that $p$ because

\footnotetext{
${ }^{5}$ In addition to the figures discussed below, Kroon (2000), McGrath (2003), Horwich (2008), and Tallant (2018) also display sympathy with the deflationary approach. Deflationism in the specific context of presentism can be spotted in Sanson and Caplan (2010), Tallant (2010), and Baia (2012). See also Lewis, who writes:
}

It is plain to see how much damage Armstrong's demand for truth-makers has done to his combinatorialism. The intuitive price is very -high — and all for nothing if, as I think, the demand for truth-makers is wrong in the first place. Yet it is not altogether wrong. I think it is an over-reaction to something right and important and under-appreciated. (1992: 218)

Some find a deflationary spirit in Lewis (e.g. MacBride 2005), but not everyone (e.g. Bricker 2015).

${ }^{6}$ Variations on this theme are a clue that deflationist thinking is nearby. Consider Melia's "Truthmaking without Truthmakers” (2005), Schnieder's “Truth-making without Truth-makers” (2006), and Rychter's “Truthmaker Theory without Truthmakers" (2014). 
$<p>$ is true (2005: 42). For example, the proposition $<$ Snow is white $>$ is true because snow is white, but it's not the case that snow is white because the proposition $<$ Snow is white $>$ is true. Hornsby argues that this explanatory task can be satisfied without positing the existence of truthmakers, and so the ambitions behind truthmaker theory can be achieved without any recourse to the truthmaker theorists' substantive ontological posits.

Echoing Hornsby's discussion is Timothy Williamson's rejection of truthmaker theory (2013: 391-403). He points to the same explanatory asymmetry above, and observes that "no metaphysically loaded truthmaker principle" is necessary in accounting for it (2013: 400). What Williamson means by 'metaphysically loaded' is unclear. But one plausible way to read this is as the idea that truthmaking can be done without positing truthmakers. Likewise, Benjamin Schnieder argues that "to claim that something makes something true, is to assert a certain explanatory relation" which usually reduces to the claim that $\langle p\rangle$ is true, when it is true, because $p$ (2006: 367). Nothing further is to be said. We certainly don't need to appeal to the idea that there are entities that make propositions true in the truthmaker theorists' sense. Pablo Rychter advocates something similar, arguing that according to his "truthmaking without truthmakers" view, for any true proposition $p$, " $p$ is true because the objects in question instantiate the properties and relations in question" (2014: 282). Again, supposedly no truthmakers are required. Finally, Trenton Merricks (2007) appears to adopt a deflationary stance, arguing that the truthmaking project for at least some truths is easily accomplished. In particular, Merricks maintains that propositions that are about the non-actual and the non-present trivially satisfy the demands of truthmaker theory and, in so doing, require no substantial ontological commitments. The proposition $<$ Fido was brown $>$ is true because Fido was brown, maintains Merricks, and that's all there is to say about the matter. Only truths about the actual and the present require a substantive truthmaker theory. ${ }^{7}$

Common to all these views is the stress on the centrality of claims to the effect that any proposition $\langle p\rangle$ is true because $p$. Another prominent deflationist voice who makes use of this asymmetry is Julian Dodd (2002, 2007). Truthmaking, for Dodd, is easy, and so the core tenets of truthmaker theory can be satisfied without recourse to contentious investigation into ontology. $\mathrm{He}$ writes: " $<a$ is $F>$ is true because $a$ instantiates $F$. For this proposition to be true, its subpropositional constituents must refer to an object and a property respectively, and the object must

\footnotetext{
${ }^{7}$ We include Merricks as a potential deflationist, but we concede that this is controversial. As Bennett (2011) argues, the notion of trivial dependence seems to have less to do with truthmaking and more to do with case-making, Bennett's phrase for the dependence of one entity on a more fundamental one. Still, it is at least plausible that Merricks is aiming for some deflationist-style view, and in that sense at least his broad approach is an example of the deflationist line of thought.
} 
instantiate the property. Given that this is so, the truth of $<a$ is F $>$ commits us ontologically only to $a$ and to F. A truthmaker would not seem to be required" (2007: 396). Dodd explicitly asserts that the schema ' $\langle p\rangle$ is true because $p$ ' is the "canonical expression" of the basic idea behind truthmaking (2007: 393; cf. Tallant 2009: 408). Account for that schema in an ontologically innocuous way, and you have done away with the need for truthmaker theory.

Deflationists about truthmaking agree that truthmaker theory, as normally practiced, is an overreaction to a fairly straightforward theoretical task: explaining the asymmetry between truth and the world. Just as deflationists about truth rely on the T-schema to explain all there is to explain about truth, deflationists about truthmaking rely on the "because-schema", or B-schema, to explain all there is to explain about truthmaking:

(B) $\quad<p>$ is true because $p$.

In this way, deflationists hope to avoid what they see as unnecessary or problematic metaphysical or ontological commitments that accompany standard truthmaker theory. The ambition, again, is to effect truthmaking without truthmakers. Our view is that this project fails. However one spells out the idea of truthmaking without truthmakers, the project either fails to satisfy its own ambitions, or collapses into ordinary truthmaker theory.

\section{Deflationary Truthmaking in Detail}

Deflationists about truthmaker theory maintain that everything that truthmaker theorists can do, they can do better: they can theorize more parsimoniously, without the ontological commitments that characterize standard truthmaker theory. To fully understand the deflationist's position, we therefore need to answer two questions. First, what is it that truthmaker theory does such that deflationist truthmaker theory does it too? Second, what are the ontological commitments that characterize standard truthmaker theory and that deflationism proceeds without? Let us take each of these questions in turn.

\subsection{The aims of truthmaking}

The central motivation behind the truthmaking project is to make good on a particular way of understanding the relationship between truth and the world, according to which truth is never brute. We state the basic principle being upheld here as follows: 
(World-to-Truth) Necessarily, truth is not a fundamental feature of reality; what is true depends upon the world.

Note that the relevant kind of dependence at issue in (World-to-Truth) is metaphysical. Each proposition depends on the world being thus-and-so for its truth. The basic idea behind (Worldto-Truth) is simply that truth never floats free of reality. The truth of a proposition is always anchored to the world in some manner. A proposition fails to be anchored to reality when the truth or falsity of the proposition can vary independently of the world. The most extreme case of this is when you have two worlds such that there is some proposition $\langle p\rangle$ that is true at one world, and false at the other, though in every other respect the worlds are exactly alike.

In order to know whether deflationist truthmaker theory is capable of upholding (Worldto-Truth) we need some sense of what a successful satisfaction of the principle would look like, where the relevant notion of success is not already tied to standard truthmaker theories. So, for instance, we cannot say that one's theory successfully satisfies (World-to-Truth) when it specifies what the truthmakers are for each and every proposition, since that would beg the question against the deflationist. Substantive truthmaker theorists satisfy (World-to-Truth) by positing truthmakers, but deflationists must do it some other way. We are interested in a very minimal success condition: what is the least one must do in order to satisfy (World-to-Truth)? We aim to make the success conditions as easy as possible for deflationists to satisfy.

Hence, we propose two straightforward conditions for the successful satisfaction of (World-to-Truth). First, it must be the case that for every true proposition $\langle p\rangle$, the truth of $\langle p\rangle$ depends on $\mathrm{Q}$, where $\mathrm{Q}$ is some feature of the world. We remain neutral here on what sort of thing Q might turn out to be (or even if Q has to be a thing at all), so as not to stack the deck in favor of truthmaker theory. This condition establishes that truth and being do in fact stand in a dependence relationship with each other.

Second, for every true proposition $\langle p\rangle$, if the truth of $\langle p\rangle$ depends on Q, then it is not possible to have $\mathrm{Q}$ without also having the truth of $\langle p\rangle$. Standard truthmaker theory meets this condition by imposing a necessitation constraint on the truthmaking relation: $\mathrm{T}$ is a truthmaker for $\langle p\rangle$ only if it's impossible for T to exist and $\langle p\rangle$ be false. ${ }^{8}$ But it's plausible to require any dependence relation to abide by a similar constraint. Without some sort of necessitation requirement, the following possibility arises. There is some proposition $\langle p\rangle$ such that its truth depends on $\mathrm{Q}$ and yet it is possible for $\mathrm{Q}$ to exist (or obtain or what have you) even in situations

\footnotetext{
${ }^{8}$ See Asay 2016 for a recent argument favoring this view.
} 
in which $\langle p\rangle$ is false. Such a case, we suspect, is one in which $\langle p\rangle$ 's truth floats free of reality and thus does not depend upon the world after all. Why? Well, in this scenario we have two worlds, the actual world $\mathrm{W}_{1}$ and $\mathrm{W}_{2}$, such that $\left\langle p>\right.$ is true at $\mathrm{W}_{1}$ and false at $\mathrm{W}_{2}$. $\mathrm{Q}$ belongs to both worlds. The question of concern to all parties is how <p>'s truth depends on the makeup of $\mathrm{W}_{1}$. The answer provided, however, applies just as well to $\mathrm{W}_{2}$. In fact, there needn't be any difference between $\mathrm{W}_{1}$ and $\mathrm{W}_{2} \_<p>$ just happens to be true in one of them but not the other. The truth of $<p>$ isn't tied down to $\mathrm{W}_{1}$ via $\mathrm{Q}$ if Q's presence in a world is consistent with $<p>$ 's falsity.

If deflationists reject these minimal constraints on satisfying (World-to-Truth), then they are welcome to offer us an alternative account that avoids them. As it stands, we believe that they provide an acceptable starting point for a neutral understanding of the nature of the dependence of truth on being. We need such a starting point before we can evaluate the deflationist claim that the B-schema all by itself satisfactorily accounts for the dependence. ${ }^{9}$

\subsection{The commitments of substantive truthmaker theory}

The deflationist program is to satisfy (World-to-Truth) without taking on the commitments of substantive truthmaker theory. But what are these commitments? This is not an easy question to answer, as truthmaker theory cannot be defined by any particular set of ontological or metaphysical commitments. Truthmaker theorists disagree amongst themselves as to which truths require truthmakers, what the nature of the truthmaking relation is, and what objects the truthmakers are. A general difficulty for deflationists is to articulate how they can avoid truthmaking commitments in general, and not just the particular commitments of particular theorists.

One way to begin is to return to the analogy with deflationary truth. Deflationists about truth deny that we need a correspondence relation or set of objects called 'facts' to fund an adequate theory of truth. So perhaps a deflationist about truthmaking would deny that we need a

\footnotetext{
${ }^{9}$ One might worry that the constraint on (World-to-Truth) should be understood directly in terms of ontological dependence, not necessitation. The trouble, dialectically speaking, is that deflationists accept that truth depends ontologically on being. They just think we can get the dependence on the cheap, by means of the B-schema. So we can't outright charge the deflationist with denying that there's ontological dependence between truth and being. Our approach, then, is to look at the kinds of things that might be involved in ontological dependence, and check to see if the deflationist has, in fact, acquired those things without giving up deflationism. Since it is often assumed that necessitation of some kind is at least necessary for ontological dependence (though not sufficient; see Fine (1995) for discussion), the appeal to necessitation seems to be one way of gaining dialectical traction on the deflationist. See Trogdon (2013) for an argument in favour of the necessity of necessitation for ontological dependence.
} 
truthmaking relation or set of objects called 'truthmakers' to fund (World-to-Truth). After all, if deflationists admit that there is a truthmaking relation, or that there are objects that are truthmakers, then they would seem to place themselves back in the camp of substantive truthmaker theory.

Most of the truthmakers that have been posited by theorists have raised the eyebrows of skeptical deflationists. States of affairs (Armstrong 2004), tropes (Simons 2005), and objects under counterpart relations (Lewis 2003) are just some of the entities that have been offered, and many find a commitment to them too much to bear. As for the truthmaking relation, most theorists nowadays maintain that it is a hyperintensional relation that holds between a proposition (or other suitable truth-bearer) and some object (its truthmaker). Necessitation is typically treated as a necessary but not sufficient condition on truthmaking. That is to say, $\mathrm{T}$ is a truthmaker for $\langle p>$ only if it's impossible for $\mathrm{T}$ to exist and $\langle p\rangle$ be false. But given that all contingent objects necessitate all necessary truths, most truthmaker theorists accept that there is more to truthmaking than necessitation. As Rodriguez-Pereyra (2005: 17) puts the point, truthmaking is an "in virtue of' relation. For $\mathrm{T}$ to be a truthmaker for $\langle p\rangle$ is for $\langle p\rangle$ to be true in virtue of the existence of T. Exactly what "in virtue of" comes to here is a matter of debate-Rodriguez-Pereyra regards it as primitive-but many think it implies that truthmaking is an explanatory relation (e.g. Griffith 2013), or that truths are in some sense about their truthmakers (Merricks 2007).

\subsection{The deflationist approach}

We are now in a position to state more precisely the deflationist position. Deflationist truthmaker theorists maintain that they can satisfy (World-to-Truth), since that is what standard truthmaker theory is in the business of doing, and deflationist truthmaker theorists hold that they can do whatever it is that standard truthmaker theorists can do. To satisfy (World-to-Truth), they do not rely on positing any truthmakers or a truthmaking relation. Instead, they turn to the instances of the B-schema, which provide the resources for justifying the deflationist slogan of "truthmaking without truthmakers". To show how truth depends on the world, it suffices to point out that for any true proposition $\langle p\rangle,\langle p\rangle$ is true because $p$. No truthmakers or contentious truthmaking relation would seem to be required. We shall argue, to the contrary, that reliance on the B-schema alone, without resorting to truthmaking and truthmakers, is insufficient for upholding (World-to-Truth). ${ }^{10}$

\footnotetext{
${ }^{10}$ Cameron (2008b: 123) suggests that some instances of the B-schema are false. While this claim, if true, would be a shortcut for our cause, we shall assume that the instances of (B) are all true.
} 


\section{Troubles for Deflationism}

As noted, there are two aspects of the deflationist project: give up on truthmakers and give up on the in virtue of relation that is supposed to constitute the dependence of truth on the world. There are, therefore, two lines of attack open to the standard truthmaker theorist: challenge the deflationist's ability to jettison truthmakers, or challenge the deflationist's ability to reject the 'in virtue of truthmaking relation. We will develop both kinds of objection.

\subsection{No truthmakers}

Deflationists claim that we can have truthmaking (i.e. we can satisfy (World-to-Truth)) without truthmakers. We envision two different ways of understanding the thesis that there are no truthmakers. Both are problematic.

The first way of articulating the thesis that there are no truthmakers is to start with the idea that all there is to being a "truthmaker" is to be something that stands in the truthmaking relation. The deflationist then claims that there is no truthmaking relation, and so, a fortiori, no truthmakers. Ultimately, we think that this is the position that deflationists should take (though we are unaware of anyone who has articulated such a perspective). However, this approach inherits all of the problems that result from denying that there is a truthmaking relation, which are the focus of the next section.

According to the second way of articulating deflationism, the deflationist accepts that there are various ontological posits that truths depend on, but maintains that these posits are not of the unsavory kind that are supposedly essential to truthmaker theory. For instance, Rychter clarifies his "truthmaking without truthmakers" view by saying that " $p$ is true because the objects in question instantiate the properties and relations in question" (2014: 282). Similarly, Dodd says that "the truth of $<a$ is $F>$ commits us ontologically only to $a$ and to $F$. A truthmaker would not seem to be required" (2007: 396). What these statements communicate is that there is a need for truths to depend on various things in the world, but that conceding this much does not yet commit one to truthmaking or to truthmakers.

One interpretation of these kinds of remarks is that they are just statements of fellow truthmaker theorists who refuse to acknowledge that they are fellow truthmaker theorists. Truthmaker theorists want to understand what sorts of ontological posits are required for truths to be true, and then commit to those posits. Rychter and Dodd do precisely that. For straightforward predicative truths, anyway, ontological commitments to the relevant objects, 
relations, and properties are said to be required. This stance is by no means uncontentious (Quine, of course, would balk at the idea that $<_{a}$ is F $>$ is committed to F), and doesn't fall outside the bounds of standard truthmaker theory. David Lewis, for instance, advances a nominalist-friendly truthmaking view that doesn't even commit to properties and relations (2003). It's clear that Rychter and Dodd do not want to commit to Armstrong's states of affairs, or the tropes of Mulligan, Simons, and Smith (1984), but avoiding those particular posits is not sufficient for exiting the truthmaking game.

An alternative interpretation of the remarks made by Rychter and Dodd is that while some ontological posits are indeed necessary to uphold (World-to-Truth), it's incorrect to think of them as being truthmakers. This might be because, to their minds, truthmakers are analytically tied to unsavory ontology. In that case, we'd like to hear a non-question begging account as to which ontological posits are acceptable. (Note well that even tables and chairs are unsavory on some metaphysical views.) Alternatively, it might be because the posits at issue fail to necessitate the truths in question. The mereological sum $a+\mathrm{F}$ (which is what Rychter and Dodd seem to have in mind) does not necessitate the truth of $<a$ is $\mathrm{F}>$ if $a$ is only accidentally $\mathrm{F}$. This second stance is more plausible, but it does raise the question as to whether these deflationists just belong to the camp of those who think truthmaking doesn't require necessitation (e.g. Parsons 1999, Briggs 2012, and Griffith 2015). In any event, those who claim we need ontology but not "truthmakers" for truth to depend on are walking a very fine (and perhaps unsustainable) line.

Let's suppose that we can solve the issue as to which ontological posits are acceptable to all parties, and that they are objects to which most people are likely to be committed to, irrespective of their perspective (if any) on truthmaking. The idea that Rychter and Dodd seem to want to express is that those entities are sufficient for upholding (World-to-Truth), and thus talk of truthmakers is just so much metaphysical bluster. If we could satisfy (World-to-Truth) with just ordinary objects and properties, then truthmaking would be easy indeed, and thoroughly unsurprising from an ontological perspective. The deflationist's solution, however, ignores the reasons why truthmaker theorists such as Armstrong called upon truthmakers in the first place. Crucially, it fails to countenance the second condition of adequacy specified in section 4.1. for satisfying (World-to-Truth).

Recall the basic idea: for every true proposition $\langle p\rangle$, if the truth of $\langle p\rangle$ depends on Q, then it is not possible to have $\mathrm{Q}$ without also having the truth of $\langle p\rangle$. As Armstrong shows, ordinary objects and properties cannot, on their own, satisfy this constraint. The easiest way to see this is to look at cases of contingent predication, such as the proposition < Suzy is wise $>$. The deflationist will hold that the truth of $<$ Suzy is wise $>$ depends upon Suzy and the property of 
wisdom. But Suzy and the property of wisdom on their own won't suffice. That's because both Suzy and the property of wisdom could exist and yet it fail to be the case that $<$ Suzy is wise $>$ is true. That is simply because Suzy might have lacked the property of wisdom, though somebody else didn't.

So the right dependence base must be some complex involving Suzy and the property in question: it must be Suzy's instantiating the property of wisdom (or, as on trope theories, the wisdom instantiated by Suzy). That's because the complex involving Suzy and the property of wisdom cannot be a part of a world without it also being the case that $<$ Suzy is wise $>$ is true. But the complex involving Suzy and the property of wisdom just is what Armstrong thinks makes the proposition $<$ Suzy is wise $>$ true; that's what he takes the truthmaker for the proposition to be. A state of affairs is nothing more than the non-mereological union of an object and a property (the 'non-mereological union' being Armstrong's phrase for 'instantiation').

The deflationist about truthmaking therefore faces a dilemma when it comes to propositions like $<$ Suzy is wise $>$. Either she thinks that the truth of that proposition depends upon objects and properties on their own, or she thinks that the truth of that proposition depends upon objects instantiating properties. In the former case, she cannot do everything that the standard truthmaker theorist can do, since it is possible for there to be two worlds that are alike in every respect except that in one world $<$ Suzy is wise $>$ is true, but in the other world that proposition is false. In the latter case, by committing to the instantiation she is actually invoking the very entities that she claims we can do without. Either way, she fails to provide a successful alternative to standard truthmaker theory.

A deflationist might retort here that although she insists that Suzy must instantiate wisdom in order for $<$ Suzy is wise $>$ to be true, admitting as much does not require there to be an entity above and beyond Suzy and wisdom; Suzy and wisdom are the only things involved. This kind of response is highly reminiscent of what Armstrong long ago labeled 'ostrich nominalism', which sees no need to posit universals to account for the truth of predications (1980). The point we wish to stress is that by not allowing states of affairs or tropes to play a role in understanding what it is for an object to instantiate a property, the deflationist leaves the facts of instantiation brute and unexplained. What sort of commitment is it, for a deflationist, to commit to Suzy's instantiating wisdom? For the standard truthmaker theorist, this commitment is just a straightforward and familiar ontological commitment. But it must be something else for the deflationist. Perhaps it's just commitment to the truth of the proposition $<$ Suzy instantiates wisdom $>$. But that looks like the original truth in question, and anyway one doesn't show how truth depends on the world by showing how one truth depends on another. So it appears that deflationists must adopt some sui 
generis form of commitment that is neither an ontological commitment to an object nor an "alethic" commitment to the truth of a proposition. Deflationists are free to do so, of course, but in so doing they abandon their claim of offering a more parsimonious account of (World-to-Truth). Whereas standard truthmaker theorists require one extra commitment of a familiar kind, deflationists now require one extra commitment of an unknown kind. ${ }^{11}$

\subsection{No truthmaking}

A second key component to the deflationist view is that there is no truthmaking relation. If deflationist truthmaker theorists were to commit to such a relation, then it would seem that deflationists are fellow truthmaker theorists after all; furthermore, we've seen that rejecting the existence of a truthmaking relation is also the best route for justifying the claim that there are no truthmakers. In rejecting the truthmaking relation, deflationists maintain that $<$ Suzy is wise $>$ is not true in virtue of the existence of some state of affairs, trope, or what have you; rather, $<$ Suzy is wise $>$ is true because Suzy is wise, and that is all there is to say on the matter.

For example, Merricks writes in the opening pages of Truth and Ontology: "That Fido is brown is true because Fido is brown. That the Trojans were conquered is true because the Trojans were conquered. That hobbits do not exist is true because hobbits do not exist. And so on. And so we might say that truth 'depends on the world'. But such 'dependence' is trivial. No one would deny it" (2007: xiii). In this passage, Merricks seems to suggest that there is no substantive truthmaking relation underlying the B-schema. Rather, there is just a trivial relation of dependence for all truths, a relation that has no ontological substance. In a similar vein, Melia (2005) denies that there is anything metaphysically substantive underlying the 'because' connective, and so there is no genuine truthmaking relation to take account of. A similar view is adopted by Williamson (2013: 393-401) who maintains that no real truthmaking relation in the world is required to satisfy the ambitions of truthmaker theory. Instead, those ambitions can be met via a version of the 'because' schema.

In brief, our objection to this dimension of deflationism is that we cannot tell the difference between the deflationist's 'because' and the truthmaker theorist's 'in virtue of. The 'in virtue of relation is assumed by many to be an explanatory notion. Presumably, the deflationist's 'because' is also supposed to mark an explanatory notion. After all, the B-schema is supposed to be distinct from the T-schema and its merely material biconditional. Plausibly, that distinctness lies in the explanatory credentials of the B-schema. The 'in virtue of' relation is also supposed to be a relation

\footnotetext{
${ }^{11}$ We owe a debt here to Pickel and Mantegani 2012, and its sagacious analysis of ostrich nominalism.
} 
of dependence, or at least capable of scaffolding such a relation. In order for the deflationist's 'because' to fully satisfy (World-to-Truth) it, too, must correspond to some notion of dependence, otherwise the claim that $<$ Suzy is wise $>$ is true because Suzy is wise is not an expression of the dependence of truth on the world. Finally, the in virtue of relation is supposed to bring with it a modal guarantee: if $<$ Suzy is wise $>$ is true in virtue of Suzy's instantiating the property of wisdom, it follows that there can be no possible case in which Suzy instantiates the property of wisdom and yet $<$ Suzy is wise $>$ is false. But so too does 'because'. If $<$ Suzy is wise $>$ is true because Suzy is wise, then had Suzy not been wise, $<$ Suzy is wise $>$ wouldn't have been true.

At first glance, then, it would seem that the deflationist hasn't offered a genuine alternative to the truthmaker theorist's 'in virtue of relation. At best, she has offered us a notational variant of the very same thing-but a variant that scores no points when it comes to theoretical or metaphysical parsimony. To this, the deflationist might respond as follows. It should be no surprise that the deflationist's 'because' so closely resembles the truthmaker theorist's 'in virtue of relation. After all, that's the whole point of deflationary truthmaker theory: to mimic standard truthmaker theory, at a fraction of the ontological cost. Despite this, there is an important difference between the truthmaker theorist's 'in virtue of' relation and the deflationary truthmaker theorist's 'because'. The difference is this: the in virtue of relation is a real relation, in the world. It is an added item of our ontology. The deflationist's 'because', by contrast, is not a relation. It is nothing more than a linguistic or sentential device. It has no ontological basis in the world whatsoever.

Melia appears to endorse this view when he writes: "Just as we can use and understand sentences involving the familiar truth-functional connectives, themselves a family of operators, without treating ' $\&$ ' and ' $\rightarrow$ ' as predicates, without treating them as relating entities, ... so we can also understand 'makes true' as a connective which, although not truth-functional, is not something which should be thought of as having relata" (2005: 78-9). By offering this kind of response, the deflationary truthmaker theorist tightens the analogy between deflationism about truthmaking and deflationism about truth. What the correspondence theorist maintains, and what the deflationist denies, is that there is a correspondence relation between truth and the facts that is partly constitutive of what truth is. Similarly, what the standard truthmaker theorist maintains, and what the deflationary truthmaker theorist denies, is that there is an in virtue of relation between truths and truthmakers that is partly constitutive of what truthmaking is. Acceptance of the T-schema involves no commitment to a correspondence relation; likewise, acceptance of the B-schema involves no commitment to a real in virtue of relation.

The first response to this deflationist reply is to point out that standard truthmaker theory is not obviously committed to its truthmaking relation being a "real relation". That is to say, if 'real 
relation' is tracking something like the sparse/abundant distinction in the metaphysics of properties literature, there is no pressure on truthmaker theorists to place truthmaking on the sparse side of the distinction. ${ }^{12}$ On Armstrong's view, truthmaking is an internal relation (2004: 9). That means that if the relata exist, the relation itself has to exist. Because truthmaking involves necessitation, we know that $\mathrm{T}$ must make true $\langle p\rangle$ in any scenario in which $\mathrm{T}$ and $\langle p\rangle$ both exist. And any relation that is internal corresponds to no universal, on Armstrong's view. So there is no sparse truthmaking relation for Armstrong-it comes at no ontological cost in his theory.

So if the deflationist's idea is that 'because' is in some sense "less metaphysical" than 'in virtue of, they can't substantiate this claim simply by saying that the former is abundant and the latter sparse. At any rate, let's grant that 'because' is just a linguistic or sentential device. (It is an English word, after all.) What matters is what sort of commitment one undertakes when one commits to truths that employ it. For example, in asserting a T-sentence, one commits to the claims expressed on both sides sharing the same truth-value. When one asserts a B-sentence, one commits to the truth of the claims expressed by both sides, and also that they stand in a further asymmetric relationship to one another. Our contention is that this relationship is no more and no less metaphysical than whatever is expressed by 'in virtue of.

To see why, first recall that the goal of truthmaker theory is to do justice to the idea that truth depends on the world, where the dependence in question is appropriately metaphysical or ontological (not merely conceptual). Standard accounts of ontological dependence, such as those employed in standard truthmaker theory, treat it as a relation of some kind, a relation between entities in the world. Deflationists, then, need to supplement their deflated truthmaker theory with a new account of the nature of ontological dependence. In particular, they need to provide an account of the relevant kind of dependence that makes no use of any relations between true propositions and the world. For as soon as some relation is posited, that relation must be made to do the same work as the in virtue of relation, at which point the deflationist may as well just adopt the standard truthmaking story. We recognize, of course, that one may well be able to develop a theory of ontological dependence that is fit for service. Our point is just that, at present, the deflationist's project is incomplete. It is not just truthmaking that they need to deflate; they need to deflate ontological dependence as well. That is a much broader project than providing a deflationist account of truthmaking, and one that deflationists about truthmaking have not yet seen the need to develop.

\footnotetext{
${ }^{12}$ See Lewis 1983 for a canonical discussion of the sparse/abundant distinction.
} 
Furthermore, it is unclear how the deflationist's 'because' is capable of doing the kind of work that the standard truthmaker theorist's 'in virtue of relation can do, once it is deflated of any metaphysical substance (assuming that some kind of broader project of deflating ontological dependence is successful). In particular, we don't see how to make the deflationist's 'because' live up to the second condition of adequacy outlined for satisfying (World-to-Truth) except by stipulation. When standard truthmaker theorists maintain that $\langle p\rangle$ is true in virtue of $T$, they are imputing some kind of structure to the world, regardless of whether it's ultimately cashed out in terms of explanation, dependence, or left primitive. By committing to that bit of structure, truthmaker theorists fund the requisite modal connection between $\mathrm{T}$ and $\langle p\rangle$. Deflationists must deny that 'because' expresses any such structure in the world, on pain of collapsing back into standard truthmaker theory. But then it's unclear that deflationists commit to anything when they commit to the B-schema: 'because' seems empty of any content. As a result, deflationists are forced to simply assert that 'because' can do the work required of it. But assertion does not make it so. Some careful account of how this 'because' notion works is needed, one that reveals exactly how it is capable of underwriting (World-to-Truth).

Presumably, such an account would involve spelling out the exact nature of the deflationist's 'because' in explanatory terms. To do this, one would need to provide some theory of explanation, around which the relationship between truth and ontology might be built. Broadly speaking, there are two approaches to explanation available: epistemic and ontic approaches (Salmon 1985, Craver 2014, Sherados 2016). Very roughly, these approaches differ over where they locate explanations. On the ontic approach, explanations are in the world: every explanation is backed by the existence of some explanatory relation between explanandum and explanans. So, for instance, according to an ontic conception of causal explanation, the causal 'because' represents the existence of causal relations that connect events in the world. ${ }^{13}$ On the epistemic approach, by contrast, explanations are in the head: explanations are not backed by the existence of any explanatory relations in the world. Rather, explanations are simply a matter of inferential relationships between knowledge states. ${ }^{14}$

The deflationary truthmaker theorist will need to treat her 'because' as an epistemic notion of explanation, not an ontic one. An ontic conception of explanation will, once more, impute the kind of relation to the world that the deflationary truthmaker theorist is at pains to avoid. If the

\footnotetext{
${ }^{13}$ For a recent defense of an ontic conception of scientific explanation, see Strevens (2014). Salmon (1985) also defends an ontic conception of causal explanation.

14 The locus classicus for the epistemic conception of explanation is van Fraassen's (1980) pragmatic approach to explanation.
} 
nature of the deflationist's 'because' is epistemic, however, then the resulting notion of ontological dependence that 'because' is being used to express (i.e. the one that is implicated in (World-toTruth)) will also become epistemic. It is, however, unclear whether an epistemic conception of ontological dependence is viable. Standard accounts of ontological dependence treat it as a worldly phenomenon, not a psychologistic one. Treating ontological dependence as a psychologistic phenomenon threatens to turn ontology itself into something 'in the head', which may be more than the deflationist is willing to sign up for. ${ }^{15}$ It hardly satisfies the deflationist aim of capturing truthmaking without any contentious consequences.

Still, suppose that the deflationist takes ontological dependence to be an epistemic phenomenon anyway and just swallows the consequences. If ontological dependence is an epistemic phenomenon, then it is bound to epistemic agents-knowers. In a world without epistemic agents, nothing ontologically depends on anything. Now, suppose that $\langle p\rangle$ is true because $p$ in the epistemic sense just described. It is possible that there are no epistemic agents. So it is possibly not the case that $\langle p\rangle$ is true because $p$. If that's right, then the B-schema fails to live up to the modal force of (World-to-Truth). It follows that the modal force of the deflationist's Bschema and the central notion of ontological dependence at issue are out of step. This makes the (epistemic) B-schema unsuitable as a basis for the ontological dependence in question.

In sum, then, the deflationists' use of 'because' results in a dilemma. This is either an epistemic notion or an ontic one. If it is ontic, then they need a posit similar to the standard truthmaker theorist's. If the notion is an epistemic one, then it won't provide the deflationary truthmaker theorist with a way to capture (World-to-Truth). Either way, deflationism offers no advance over standard truthmaker theory.

\section{Diagnosing Deflationism}

Deflationary truthmaking is the claim that one can account for the plausible idea that truth depends on being without taking on the kinds of theoretical commitments required by truthmaker theory. The strategy deflationists have adopted amounts to denying the existence of truthmakers and a truthmaking relation, and relying solely on the B-schema to underwrite (World-to-Truth). We have argued that the deflationary project fails. However one develops the view, it either fails

\footnotetext{
15 Miller and Norton (2017) provide an account of grounding according to which grounding is treated as a psychological phenomenon that we project on to the world. The deflationist may be able to use the broad Miller and Norton line to develop an epistemic version of their position. Whether such a view is a genuine truthmaker theory is an interesting question, but not one that we have the space to discuss here.
} 
to capture (World-to-Truth), or does so only because it collapses into the kind of truthmaker theory that it supposedly rejects.

Why, then, has deflationism been so appealing? We offer three hypotheses as to why the view might seem compelling. First, there is a temptation to conflate the theoretical commitments of truthmaker theory in general with the commitments of particular truthmaker theorists. Armstrong's brand of truthmaking is particularly well-known and particularly strong-it requires truthmakers for every truth, and the existence of states of affairs (including an infamous totality state of affairs). But to reject Armstrong's view is not to reject truthmaking on the whole. Other truthmaker theorists have defended more modest accounts—even ones that are compatible with various brands of nominalism. We suspect that many philosophers assume that the theory of truthmaking comes front-loaded with many metaphysically extravagant commitments; we hope this paper helps provide a better understanding of the minimal commitments of truthmaker theory.

Second, we think that deflationists operate with too narrow a conception of the truthmaking enterprise. This fact was evident earlier when we saw Dodd identify the B-schema as the "canonical expression" of truthmaker theory. Hornsby makes a similar claim when she identifies truthmaking's fundamental purpose as the project of explaining an asymmetry. These understandings of truthmaking naturally stack the deck in favor of deflationism. If truthmaking is just about accounting for the fact that $\langle p\rangle$ is true because $p$ but not the reverse, then of course the $\mathrm{B}$-schema is all one needs. But this perspective misses a key component-perhaps the key component—of the ambitions of truthmaker theory. Truthmaker theory, we noted, provides a means for assembling an ontology. ${ }^{16}$ Develop a theory of truthmakers, and you produce an ontology. Hence, a complete theory from a standard truthmaker theorist provides an answer to the canonical ontological question 'What is there?' A complete theory from a deflationary truthmaker theorist provides nothing close to that. Deflationists offer a long list of instances of the B-schema, and nothing else.

One way to dramatize this point is to conceive of truthmaker theorists as attempting to balance their ontological and alethic commitments. An "alethic commitment" is taking some proposition to be true. In so doing, truthmaker theorists consider what ontological commitment, if any, is necessary to fund that alethic commitment. After considering the ontological commitments that follow from all their alethic commitments, truthmaker theorists arrive at an ontological worldview. When deflationists take on alethic commitments, they simply take on another alethic commitment: the relevant instance of the B-schema. Truthmaking, for them,

\footnotetext{
${ }^{16}$ See also Rettler (2016), who adopts a generalised account of ontological commitment in terms of truthmaking.
} 
doesn't take one from truth to ontology; it takes them from one truth to another. Deflationary truthmaker theory doesn't answer the question of what there is, and so in no way succeeds in doing everything that standard truthmaker theory does, let alone doing it better.

Finally, we suspect that deflationists might be conflating truthmaking and semantic ascent/descent. Semantic ascent is the shift from discussing propositions "about the world" to propositions "about propositions". When one asserts the proposition $<$ Snow is white $>$ one makes a claim about the color of snow. One can also semantically ascend and assert the proposition $<<$ Snow is white $>$ is true $>$, in which case one ascribes a truth-value to a proposition. One function of the truth predicate (in fact the key function, according to disquotationalists) is to enable us to semantically ascend and descend between these different propositions at different levels (Quine 1970).

A natural and plausible thought is that the propositions higher up the semantic ladder are in some sense derivative when compared to the ones at the bottom. Hence, $\langle p\rangle$ is prior to $\langle<p\rangle$ is true $>$, which is prior to $\langle<\langle p\rangle$ is true $>$ is true $>$, and so on. They will all necessarily share the same truth-value, of course (at least, setting aside concerns arising from truth-value gaps). But that is not to say that there is no asymmetric relationship of dependence to be found between them. It is precisely this line of thought that informs Kripke's (1975) response to the liar paradox (i.e. that paradoxical sentences never "bottom out" in a grounded proposition), and it's likely the truthmaking deflationists are appealing to something similar. The bottom level proposition $\langle p\rangle$ is prior to the ascended proposition $\langle\langle p\rangle$ is true $\rangle$. This relationship of priority is, we hypothesize, what deflationists identify as the relationship of interest to truthmaker theory. We cement and uphold our grasp of this relationship by asserting that $\langle p\rangle$ is true because $p$.

We are happy to grant that there is some sort of priority to be found between $\langle p\rangle$ and $<\langle p\rangle$ is true $>$. The former, for instance, seems to be conceptually prior in that understanding it appears to require a proper subset of the concepts needed to understand the latter. The former involves all the concepts necessary for understanding $\langle p\rangle$, whereas the latter requires, in addition, the concepts of a proposition, truth, and perhaps even semantic ascent. What we deny, however, is that the ontological priority of interest to truthmaker theory is the priority of $\langle p\rangle$ over $\langle<p\rangle$ is true $>.{ }^{17}$ The deflationist position amounts to the claim that the truth of $\langle\langle p\rangle$ is true $>$ (which

\footnotetext{
${ }^{17}$ Liggins (2016) has recently argued that the asymmetry expressed by instances of the B-schema are best understood metaphysically, not conceptually. Though his discussion does not engage the issue of truthmaking, he is critical of how philosophers we've identified as truthmaking deflationists (such as Horwich, Schnieder, and Dodd) understand the instances of the B-schema. How exactly the instances of the B-schema are to be interpreted is not our primary goal, so we can remain neutral regarding Liggins's view. What we defend is that, whatever the instances of the B-
} 
is a semantically ascended claim "about truth") is dependent upon the truth of $\langle p\rangle$ (which is a claim "about the world"). But this leaves open our basic truthmaking question: what does the truth of $\langle p\rangle$ depend upon?

The deflationist might reply that we are misreading the B-schema. To say that $\langle p\rangle$ is true because $p$ is not to say that the truth of $\langle\langle p\rangle$ is true $\rangle$ depends upon the truth of $\langle p\rangle$. That claim, if anything, is captured by a different instance of the B-schema: $\langle<p\rangle$ is true $>$ is true because $\langle p\rangle$ is true. So in fact, the B-schema does tell you what makes $\langle p\rangle$ true: it tells you that what makes $\langle p\rangle$ true is whatever $\langle p\rangle$ is about. This line of thought is evident in deflationist writings. Dodd writes that $\langle a$ is $F>$ is true because $a$ instantiates $F$ (2007: 396). Rychter writes that $\langle p\rangle$ is true because "the objects in question instantiate the properties and relations in question" (2014: 282). Sanson and Caplan assert that $<$ Arnold was pale $>$ is true because Arnold once instantiated the property being pale (2010: 37-8). Tallant offers as a truthmaking principle: "For every proposition, that proposition is true iff it accurately characterizes its subject matter" (2010: 503).

What unites all of these cases is that in order to spell out what makes a proposition true, the author offers what amounts to a rephrasing of the truth in question (or, in Tallant's case, a synonym for 'true'). To say that $a$ instantiates $F$ is just a roundabout way of saying that $a$ is $F$. To say that Arnold once instantiated the property of being pale is just a roundabout way of saying that Arnold was pale. The deflationists appear to write as if their rephrasings are ontologically transparent, and that attending to them will solve all the ontological questions in the neighborhood. But that isn't the case. We can still ask what it is in virtue of which $a$ instantiates $F$. Is it a state of affairs? A trope? The individual $a$ standing in a counterpart relation? What's important is that this question doesn't answer itself, it just raises a further truthmaking question. By giving us yet another truth in answer to a truthmaking query, deflationists push the original question back a step: if what makes it true that Arnold was pale is that Arnold once instantiated the property being pale, then what makes it true that Arnold once instantiated the property being pale?

In sum, then, understood as semantic descent, the B-schema takes us from one true proposition $(<<p>$ is true $>)$ to another $(<p>)$. That is certainly an easy journey to take, and taking that step may well be traveling down the ladder of conceptual priority. But it's not an ontological journey. We land at another truth instead of what we really want: an account of what in the world a given truth depends upon. As we see it, the only game in town for offering such an account is truthmaker theory. ${ }^{18}$

schema are, they do not exhaust the truthmaking program.

${ }_{18}$ Our thanks go to the referees for the journal for their helpful, constructive feedback. Work on this paper was partly funded by two Australian Research Council grants (DE180100414 and DP180100105) and by the Research Grants 


\section{References}

Armstrong, D. M. (1980) 'Against "Ostrich" Nominalism: A Reply to Michael Devitt', Pacific Philosophical Quarterly 61/4: 440-9.

— (2004) Truth and Truthmakers. Cambridge: CUP.

Asay, J. (2016) 'The Facts about Truthmaking: An Argument for Truthmaker Necessitarianism', Ergo 3/18: 493-500.

Baia, A. (2012) 'Presentism and the Grounding of Truth', Philosophical Studies 159/3: 341-56.

Bennett, K. (2011) 'Truthmaking and Case-Making', Philosophy and Phenomenological Research 83/1: $187-95$.

Blackburn, S. (1984) Spreading the Word: Groundings in the Philosophy of Language. Oxford: Clarendon Press.

Bricker, P. (2015) 'Truthmaking: With and Without Counterpart Theory', in B. Loewer and J. Schaffer (eds.) A Companion to David Lewis, 159-87. Oxford: Wiley Blackwell.

Briggs, R. (2012) 'Truthmaking Without Necessitation', Synthese 189/1: 11-28.

Cameron, R. P. (2008a) 'How to be a Truthmaker Maximalist', Noûs 42/3: 410-21.

- (2008b) 'Truthmakers, Realism and Ontology', Philosophy 83: 107-28.

Craver, C. F. (2014) 'The Ontic Account of Scientific Explanation', in M. I. Kaiser et al. (eds.) Explanation in the Special Sciences: The Case of Biology and History, 27-52. Dordrecht: Springer Verlag.

Dodd, J. (2002) 'Is Truth Supervenient on Being?', Proceedings of the Aristotelian Society (New Series) 102/1: 69-85.

- (2007) 'Negative Truths and Truthmaker Principles', Synthese 156/2: 383-401.

Fine, K. (1995) 'Ontological Dependence', Proceedings of the Aristotelian Society 95: 269-290.

Griffith, A. M. (2013) 'On Some Alleged Truthmakers for Negatives', Thought 1/4: 301-8.

- (2015) 'How Negative Truths are Made True', Synthese 192/1: 317-35.

Hornsby, J. (2005) 'Truth Without Truthmaking Entities', in H. Beebee and J. Dodd (eds.) Truthmakers: The Contemporary Debate, 33-47. Oxford: Clarendon Press.

Horwich, P. (1990) Truth. Oxford: Basil Blackwell.

— (2008) 'Being and Truth', Midwest Studies in Philosophy 32/1: 258-73.

Jago, M. (2018) What Truth Is. Oxford: OUP.

Kripke, S. A. (1975) 'Outline of a Theory of 'Truth', Journal of Philosophy 72/19: 690-716.

Council of the Hong Kong Special Administrative Region, China (HKU 23400014). 
Kroon, F. W. (2000) 'Truthmaking and Fiction', Logique et Analyse 43/169-70: 195-210.

Lewis, D. (1983) 'New Work for a Theory of Universals', Australasian Journal of Philosophy 61/4: $343-77$.

— (1992) 'Critical Notice [of D. M. Armstrong, A Combinatorial Theory of Possibility]', Australasian Journal of Philosophy 70/2: 211-24.

- (2003) 'Things qua Truthmakers', in H. Lillehammer and G. Rodriguez-Pereyra (eds.) Real Metaphysics: Essays in Honour of D. H. Mellor, 25-42. London: Routledge.

Liggins, D. (2016) 'Deflationism, Conceptual Explanation, and the Truth Asymmetry', Philosophical Quarterly 66/262: 84-101.

MacBride, F. (2005) 'Lewis's Animadversions on the Truthmaker Principle', in H. Beebee and J. Dodd (eds.) Truthmakers: The Contemporary Debate, 117-40. Oxford: Clarendon Press.

McGrath, M. (2003) 'What the Deflationist May Say about Truthmaking', Philosophy and Phenomenological Research 66/3: 666-88.

Melia, J. (2005) ‘Truthmaking without Truthmakers', in H. Beebee and J. Dodd (eds.) Truthmakers: The Contemporary Debate, 67-84. Oxford: Clarendon Press.

Merricks, T. (2007) Truth and Ontology. Oxford: Clarendon Press.

Miller, K. and J. Norton (2017) 'Grounding: It's All in the Head', Philosophical Studies 174/12: 305981.

Mulligan, K., P. Simons, and B. Smith (1984) 'Truth-makers', Philosophy and Phenomenological Research 44/3: 287-321.

Parsons, J. (1999) 'There is no 'Truthmaker' Argument Against Nominalism', Australasian Journal of Philosophy 77/3: 325-34.

Pickel, B. and N. Mantegani (2012) 'A Quinean Critique of Ostrich Nominalism', Philosophers' Imprint 12/6:1-21.

Quine, W. V. (1970) Philosophy of Logic. Englewood Cliffs, NJ: Prentice-Hall.

- (1990) Pursuit of Truth. Cambridge: Harvard University Press.

Rettler, B. (2016) 'The General Truthmaker View of Ontological Commitment', Philosophical Studies 173/5: 1405-25.

Rodriguez-Pereyra, G. (2005) 'Why Truthmakers', in H. Beebee and J. Dodd (eds.) Truthmakers: The Contemporary Debate, 17-31. Oxford: Clarendon Press.

Rychter, P. (2014) 'Truthmaker Theory without Truthmakers', Ratio (New Series) 27/3: 276-90.

Saenz, N. (2014) 'The World and Truth about What is Not', Philosophical Quarterly 64/254: 82-98.

Salmon, W. C. (1985) 'Scientific Explanation: Three Basic Conceptions', PS A:

Proceedings of the Biennial Meeting of the Philosophy of Science Association 2: 293-305. 
Sanson, D. and B. Caplan (2010) 'The Way Things Were', Philosopby and Phenomenological Research 81/1: 24-39.

Schnieder, B. (2006) 'Truth-Making without Truth-Makers', Synthese 152/1: 21-46.

Sheredos, B. (2016) 'Re-Reconciling the Epistemic and Ontic Views of Explanation' Erkenntnis 81/5: 919-49.

Simons, P. (2005) 'Negatives, Numbers, and Necessity: Some Worries about Armstrong's Version of Truthmaking', Australasian Journal of Philosophy 83/2: 253-61.

Simpson, M. (2014) 'Defending Truthmaker Non-Maximalism', Thought 3/4: 288-91.

Strevens, M. (2008) Depth: An Account of Scientific Explanation. Cambridge: Harvard University Press.

Tallant, J. (2009) 'Presentism and Truth-Making', Erkenntnis 71/3: 407-16.

— (2010) 'Still Cheating, Still Prospering', Analysis 70/3: 502-6.

- (2018) Truth and the World: An Explanationist Theory. London: Routledge.

Trogdon, K. (2013) ‘Grounding: Necessary or Contingent?’, Pacific Philosophical Quarterly 94/4: 46585.

van Fraassen, B. C. (1980) The Scientific Image. Oxford: OUP.

Vision, G. (2005) 'Deflationary Truthmaking', European Journal of Philosophy 13/3: 364-80.

Williamson, T. (2013) Modal Logic as Metaphysics. Oxford: OUP. 